(III) Heated at $100^{\circ} \mathrm{C}$. for an hour with ten parts sulphuric acid, lemon yellow color.

(IV) Characteristic reaction of precipitation when heated in aqueous solution.

Parsons (Am. Chem. J., 4,39) gives the results of an examination of "scale from sorghum-sugar pans," and concludes that the "scale is a two-thirds metallic calcic aconitate (as this is a quotation we do not feel at liberty to change from Parsons' own words to "dicalcium aconitate") containing one molecule of combined water." Comparing Parsons' data with those obtained in these more recent researches it seems probable that the aconitic acid is a product formed in manufacture. The scale examined by Parsons was derived from pans in which the boiling was conducted under atmospheric pressure. The scale recently examined came from evaporators in which the boiling was done in vacuo. Inasmuch as citric acid when strongly heated loses one molecule of water and becomes aconitic according to the equation, $\mathrm{C}_{8} \mathrm{H}_{8} \mathrm{O}_{7}-\mathrm{H}_{2} \mathrm{O}=\mathrm{C}_{8} \mathrm{H}_{8} \mathrm{O}_{6}$, it is probable that Parsons' scale formed under high temperature and prolonged heating may have suffered dehydration and become an impure calcium aconitate. It would appear also that the scale formed in the evaporating apparatus of sorghum-sugar houses contains little, if any, aconitate. At the same time it may be conjectured that the reported presence of aconitic acid in the refuse or final products of sugar cane houses, molasses, skimmings, etc., may be attributed to formation in the manufacturing processes and not to presence in the canes or juices.

\title{
A CRYSTALLINE CHROMIUM TUNGSTATE.
}

BY EDGAR F. SMITH AND HERMAN L. DIECK.

Receired June 27, 1893.

DoTASSIUM bichromate was brought together with an
equivalent amount of pure tungstic plied to the mixture; fusion followed and the mass was held in this condition until the evolution of gas bubbles ceased. The temperature was never higher than necessary to maintain a liquid condition of the mixture. After cooling, the fused mass 
was treated with water until the latter ceased to dissolve anything. Sodium hydroxide and ammonium hydroxide were next enployed for washing purposes, and these finally displaced by pure distilled water. The well-washed substance was carefully dried at $100^{\circ}$. It showed a dark brown color, and when examined under the microscope revealed the presence of acicular, brown-colored crystals of orthorhombic outline; associated with these were green-colored crystals, which were apparently of the same crystallographic system. This mixture was exposed to the action of aqua regia for an hour; it was then filtered, washed, and dried. A re-examination of the browir residue showed that the green crystals had been removed and that the brown-colored body alone remained. It had been unaffected by the acid. Two weighed portions of the mixed crystals were treated with aqua regia, the acid solutions evaporated, the residues dissolved in water, and the aqueous solutions treated with ammonium hydroxide. Chronium hydroxide was precipitated. In the one case the ignited oxicle equaled 2.89 per cent. and in the other 2.92 per cent. of the original mixture. A sufficient quantity of pure brown crystals was prepared for analysis. We first endeavored to effect their decomposition by fusion with sodium carbonate and sulphur. Several attempts demonstrated that this course offered little chance of a satisfactory analysis. Digestion with hydrofluoric acid gave a poor result; the acid failed to completely decompose the material. Portions of the substance were next ignited in a current of hydrogen, the residue then oxidized with aqua regia, evaporated to dryness and treated with ammonium hydroxide. Considerable tungsten was removed in this manner, but much remained with the chromium, from which it seemed almost impossible to free it. The mixture of tungstic and chronium oxides was ignited a second time in hydrogen and again treated with aqua regia. This operation was repeated until no more tungsten could be extracted. Combining the separate portions of tungstic oxide, their total quantity gave 88.37 per cent. $\mathrm{WO}_{3}$. The chromium oxide, previously associated with this amount of tungstic oxide, equaled after careful purification, II.75 per cent. This method of analysis having proved tedious and time-consuming, we de- 
termined to try fluxing the brown-colored material with a mixture of pure sodium carbonate and potassium nitrate, as we had previously satisfied ourselves that it did not contain the alkali metals. The fusion was taken up with water, acidulated with hydrochloric acid, and evaporated to dryness. Tungstic acid separated; the residue was moistened with acid and again evaporated. It was then digested with acid and left pure tungsten trioxide which was filtered, washed, and weighed. It equaled 88.08 per cent. The chromium oxide in the filtrate, after precipitation and purification, equaled $\mathrm{r} 2.10$ per cent. Upon repeating this course with new portions of the substance we obtained results that agreed with those just given, so that we feel satisfied that they represent the true composition of the brown crystals. Taking the mean of the percentages of the two analyses given above as a basis of calculation we deduce as the most probable ratio, $\mathrm{ICr}_{2} \mathrm{O}_{3}, 5 \mathrm{WO}_{3}$ or $\mathrm{Cr}_{2} \mathrm{O}_{3} .5 \mathrm{WO}_{3}$. The theoretical requirements of this formula are:

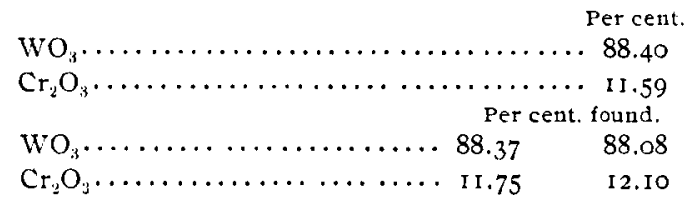

Tungstates of chromium that exist ${ }^{\prime}$ are hydrous and have been prepared by double decomposition in the wet way. The salt we describe is, so far as we can ascertain, the first of its class.

UNIVERSITY OF PENNSYLANIA, June 15,1893 .

\section{THE METHODS OF TESTING FATS AND OILS.}

BY DR. FR NEST MILLIAU, DIRECTOR OF THE GOVERNMENT TESTING LABORAtORY, MaR. SEILIES. FRANCE,

Kead befure the New York Section May 29,1893 .

$\prod \begin{gathered}\text { HE difficulties of chemical analyses of fatty matters are } \\ \text { greatly increased, not only by the slight differences which }\end{gathered}$ characterize the various glycerides, but also by the numerous cases of isomerism, and the phenomena of oxidation and fermentation which modify their molecular structures, the resins and the essen-

' Fremy's Encyclopedie Chimique, 3, 166.

$7-14-93$ 